\title{
A Two Phase M/G/1 Feedback Queue with Multiple Server Vacation
}

\author{
${ }^{1}$ K.Hemamalini, ${ }^{2}$ R.Abinaya \\ ${ }^{1,2}$ Assistant Professor, Department of Mathematics, Dr.SNS Rajalakshmi College of Arts and Science, \\ Coimbatore ,Tamil Nadu, India .
}

Abstract: In this paper, deals with the two a single server vocation queueing model with feed back. In which the server provides two types of service and each arriving customer has the option of choosing either type is studied.

Keywords: $P_{n}^{(1)}, P_{n}^{(2)}, V_{n}, W_{q}, L_{q}, \lambda, t$.

\section{Introduction}

A two phase M/G/1 queueing system with Bernoulli feedback where the server takes multiple vacation is analysed in this paper. All the customers demand first essential service, whereas only some of them demand second optional service. After the completion of the first service or second service, if the customer is dissatisfied with its service, he can immediately join the tail of the queue as a feedback customer for receiving another regular service. Otherwise the customer may depart forever from the system. If there is no customer in the queue then the server goes for multiple vacation and the vacation periods are exponentially distributed. the time dependent probability generating functions in terms of their Laplace transforms and the corresponding steady state results are derived. Further the mean queue length and mean waiting time are obtained. Numerical results are presented.

\section{Governing Equations}

Define, $\mathrm{P}_{\mathrm{n}}{ }^{(1)}(\mathrm{x}, \mathrm{t})=$ Probability that at time $\mathrm{t}$, there are $\mathrm{n}(\geq 0)$ customers in the queue excluding the one being provided the first essential service and the elapsed service time of this customer is $\mathrm{x}$.

$\mathrm{P}_{\mathrm{n}}^{(2)}(\mathrm{x}, \mathrm{t})=$ Probability that at time $\mathrm{t}$, there are $\mathrm{n}(\geq 0)$ customers in the queue excluding the one being provided the second essential service and the elapsed service time of this customer is $\mathrm{x}$.

$\mathrm{V}_{\mathrm{n}}(\mathrm{t})=$ Probability that at time $\mathrm{t}$, there are $\mathrm{n}(\geq 0)$ customers in the queue and the server is on vacation. The system is then governed by the following set of differential difference equations.

$$
\begin{aligned}
& \frac{\partial}{\partial x} P_{n}^{(1)}(x, t)+\frac{\partial}{\partial t} P_{n}^{(1)}(x, t)+\left(\lambda+\mu_{1}(x)\right) P_{n}^{(1)}(x, t)=\lambda P_{n-1}^{(1)}(x, t), n \geq 1 \\
& \frac{\partial}{\partial x} P_{0}^{(1)}(x, t)+\frac{\partial}{\partial t} P_{0}^{(1)}(x, t)+\left(\lambda+\mu_{1}(x)\right) P_{0}^{(1)}(x, t)=0 \\
& \frac{\partial}{\partial x} P_{n}^{(2)}(x, t)+\frac{\partial}{\partial t} P_{n}^{(2)}(x, t)+\left(\lambda+\mu_{2}(x)\right) P_{n}^{(2)}(x, t)=\lambda P_{n-1}^{(2)}(x, t), n \geq 1 \\
& \frac{\partial}{\partial x} P_{0}^{(2)}(x, t)+\frac{\partial}{\partial t} P_{0}^{(2)}(x, t)+\left(\lambda+\mu_{2}(x)\right) P_{0}^{(2)}(x, t)=0 \\
& \frac{d}{d t} V_{0}(t)=-(\lambda+\gamma) V_{0}(t)+(1-r) q \int_{0}^{\infty} P_{0}^{(1)}(x, t) \mu_{1}(x) d x \\
& \quad+q \int_{0}^{\infty} P_{0}^{(2)}(x, t) \mu_{2}(x) d x+\gamma V_{0}(t) \\
& \frac{d}{d t} V_{n}(t)=-(\lambda+\gamma) V_{n}(t)+\lambda V_{n-1}(t), n \geq 1
\end{aligned}
$$

With boundary conditions , 


$$
\begin{aligned}
& \mathrm{P}_{0}^{(1)}(0, \mathrm{t})=(1-\mathrm{r}) \mathrm{q} \int_{0}^{\infty} \mathrm{P}_{1}^{(1)}(\mathrm{x}, \mathrm{t}) \mu_{1}(\mathrm{x}) \mathrm{dx}+\mathrm{q} \int^{\infty} \mathrm{P}_{1}^{(2)}(\mathrm{x}, \mathrm{t}) \mu_{2}(\mathrm{x}) \mathrm{dx}
\end{aligned}
$$

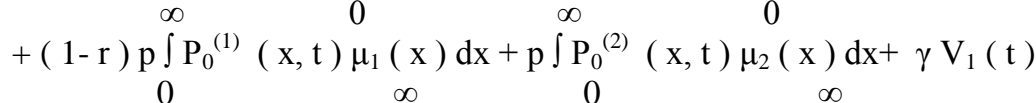

$$
\begin{aligned}
& P_{n}^{(1)}(0, t)=(1-r) q \int P_{n+1}^{\infty}(x, t) \mu_{1}(x) d x+q \int P_{n+1}^{\infty}(2)(x, t) \mu_{2}(x) d x+(1-r) p \int P_{n}^{(1)}(x, t) \mu_{1}(x) \\
& \infty \quad 0 \\
& 0 \\
& d x+p \int P_{n}^{(2)}(x, t) \mu_{2}(x) d x+\gamma V_{n+1}(t), n \geq 1 \\
& \mathrm{P}_{\mathrm{n}}^{(2)}(0, \mathrm{t})=\mathrm{r} \int_{0}^{\infty} \mathrm{P}_{\mathrm{n}}^{(1)}(\mathrm{x}, \mathrm{t}) \mu_{1}(\mathrm{x}) \mathrm{dx}, \mathrm{n} \geq 0
\end{aligned}
$$

Assume that initially there is no customer in the system and the server is under vacation, so that the initial conditions are

$\mathrm{V}_{0}(0)=1, \mathrm{~V}_{\mathrm{n}}(0)=0$ and $\mathrm{P}_{\mathrm{n}}^{\mathrm{j}}(0)=0$ for $\mathrm{n}=0,1,2, \ldots \mathrm{j}=1,2$.

\section{The Mean Waiting Time}

The mean waiting time in the queue is given by

$$
\begin{aligned}
& \mathrm{W}_{\mathrm{q}}=\frac{\mathrm{L}_{\mathrm{q}}}{\lambda} \\
& =\frac{\lambda\left[\mathrm{q}\left[\mathrm{E}\left(\mathrm{v}_{1}{ }^{2}\right)+\mathrm{rE}\left(\mathrm{v}_{2}{ }^{2}\right)+2 \mathrm{rE}\left(\mathrm{v}_{1}\right) \mathrm{E}\left(\mathrm{v}_{2}\right)\right]+2 \mathrm{p}\left[\mathrm{E}\left(\mathrm{v}_{1}\right)+\mathrm{rE}\left(\mathrm{v}_{2}\right)\right]^{2}\right]}{2 \mathrm{q}^{2}} \int \frac{\lambda \mathrm{E}\left(\mathrm{v}_{1}\right)-\mathrm{r} \lambda \mathrm{E}\left(\mathrm{v}_{2}\right)}{\mathrm{q}} \\
& \mathrm{W}=\frac{\mathrm{L}}{\lambda} \\
& =\lambda\left[\mathrm{q}\left[\mathrm{E}\left(\mathrm{v}_{1}^{2}\right)+\mathrm{rE}\left(\mathrm{v}_{2}^{2}\right)+2 \mathrm{rE}\left(\mathrm{v}_{1}\right) \mathrm{E}\left(\mathrm{v}_{2}\right)\right]+2 \mathrm{p}\left[\mathrm{E}\left(\mathrm{v}_{1}\right)+\mathrm{rE}\left(\mathrm{v}_{3}\right)\right]^{2}\right]
\end{aligned}
$$

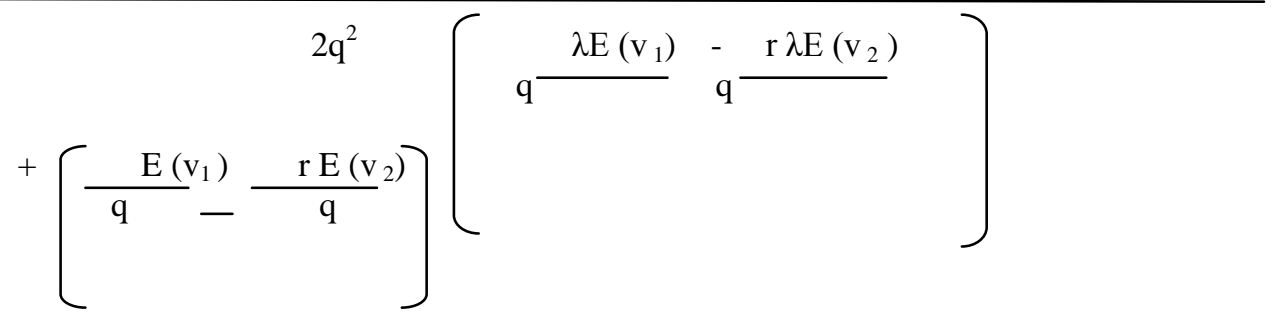

$1-$

$1-$

\section{Conclusion}

Two the system is analyzed by assuming all the Poisson arrivals demand first essential service, but some of them

for second optional service. If there is no customer in the queue then the server goes for multiple vacations.

\section{REFERENCES}

[1]. Choudhury, G., (2003). Some aspects of an M/G/1 queueing system with optional second service, TOP, 11, 141-150.

[2]. Thangaraj, V.and Vanitha, S. (2009). A two phase M/G/1 feedback queue with multiple server vacation , Stochastic Analysis and Applications , 27, 1231-1245.

[3]. Krishnakumar, B., Vijayakumar, A.and Arivudainambi,D., (2002).An M/G/1 retrial queueing system with two phase service and preemptive resume, Annals of Operations Research , 113,61-79.

[4]. Jewkes, E.M. and Buzacott, J.A., (1991). Flow time distributions in a K class M/G/1 spriority feedback queue, queueing systems, 8, 183-202.

[5]. Thangaraj,V.and Vanitha, S., (2010). A single server M/G/1 feedback queue with two types of service having general distribution, international Mathematical Forum,1,15-33. 